\title{
基于新型地理信息系统技术在工程测量中的应用研究探析
}

张金花

玉林市国土资源规划测绘信息院

DOI:10.32629/gmsm.v3i2.618

[ 摘 要] 在整个项目的建设过程中,工程测量贯穿与整个项目的始末, 随着国民经济的不断发展,建设项目越来越多的新技术被引进其中,并且 在整个项目中发挥着日益增长的作用, 对此相关企业认识到工程测量的重要性,为工程建设提供数据保障。新型地理信息系统技术在工程测量中 得到了广泛的应用,全面提高了工作效率,保证了测量的精度,在未来发展中有着良好的前景。技术在不断创新,新型地理信息系统技术在未来还 有很长的路要走, 只有全面强化科研投入,推动产业化发展,才能有效实现技术创新,有力的带动工程测量质量提升。基于此,论文阐述了地理信息 系统的相关内容,研究了地理信息系统在测绘中的应用。

[关键词] 地理信息技术; 工程测量; 地理信息系统

地理信息系统得以在工程测量中实现广泛应用, 因其具有极为鲜明的 特点, 相对于其他系统所具备的优势十分显著, 外部因素不会对其造成太 大影响。地理信息系统包含的技术较多, 且十分先进, 不会受外界较大影响 的 GIS技术, 即便在恶劣环境下也能为技术提供优良性保障。而因测绘工 作开展区域十分多, 可能存在任何环境, 工作人员需要较高的技术水平且 不会受环境太大影响的技术。该技术同时也具备较高的监测效率、测量数 据精确度优势, 能为现有测绘工作的开展提供极大便利。

\section{1 地理信息系统的应用对工程测量工作起到的作用}

1. 1 全面提高工作效率

通过GIS系统的全面应用, 能够有效提升工作的效率, 确保成果质量。 GIS系统主要是在计算机技术的基础上, 对各种地理信息进行快速的采集 的处理, 能够全面保证数据的精准性, 和传统的测绘方法相比, 有一定的保 障, 以往的测绘主要是靠人工实地勘测来完成, 各种信息的获取需要大量 的时间成本, 同时也无法保证数据的完整性, 而通过先进技术的运用, 就能 大大减少工作量, 有效的节省了时间, 利用大数据信息库对数据进行分析、 处理, 能在最短时间内完成地图测绘分析, 进一步简化了工作流程, 提高了 工作效率。

\section{2 时效性更强}

使用先进的技术进行测绘, 能够全面进行多项运行, 测绘过程中, 技术 人员通过数据库信息汇总, 就能够对所测绘的数据进行核对, 直观查看所 需要数据的相关信息, 对数据出现的变化进行纠正, 保证了数据的精准度, 测绘信息时刻保持较高的精度, 时效性更强。

1. 3增强可靠性

数据测绘需要保证质量, 避免出现数据误差, GIS系统通过计算机模型 对各种数据进行处理, 和以往人工计算相比, 能够避免误差, 虽然做不到零 误差, 但能够保证结果和质量, 使数据更加精准, 较好的为工程建设提供优 质地理测绘服务。

\section{2 地理信息系统技术在工程测量中的应用}

2. 1 在变形监测中的应用

项目建设过程中, 需要及时对各部分进行纠正, 保证建筑物的安全稳 定, 通过良好的技术应用, 能够对变形情况进行分析, 推动工程建设顺利进 行。通过地理信息系统技术及GPS技术对施工进行监测, 全面对各种数据进 行分析。新型地理信息技术可以有效监测工程变形的情况, 因为工程会受 地壳运动因素影响发生一些变形, 水利工程大坝变形、地表沉降变形等均 影响到项目的安全。通过建筑物变形监测, 及时传递信息, 使相关的设计能 够及时调整, 保证结构的稳固, 进一步降低项目建设危险, 并及时止损, 维
护良好的经济效益。

2. 2 在地质勘查灾害预测工程中的应用

我国是一个地质灾害多发的国家, 地质灾害所带来的后果影响是非常 巨大且深远的, 严重威胁到人民群众的生命及财产安全, 譬如地震灾害、火 山喷发灾害等都是灾害影响范围及程度很大的地质灾害类型。因此, 提前 预测地质灾害对于帮助人民群众减少财产损失及降低生命威胁都有着极 其重要的作用。测绘地理信息技术的开发恰好具备这一功能, 国家地质灾 害管理总局将测绘地理信息技术应用到地质灾害的预测及防治工作当中, 通过该技术对地质灾害发生前的特殊地理信息加以数据分析, 从而确定地 质灾害发生区域及地质灾害类型, 帮助人民群众及时进行财产转移及撤离 工作, 降低人民群众财产损失。当前, 正是由于测绘地理信息技术的引入使 得地质灾害预测系统日臻完善, 譬如前些年国家地质灾害管理总局就成功 预测出重庆市某县级地区地震灾害及洪涝灾害, 以及桂林市某区域发生的 岩溶灾害, 及时组织和疏散人民群众撤离, 降低了人民群众的损失。

2. 3在地形测量中的应用

通过新型地理信息系统技术能够全面保证数据的准确性, 在项目建设 中也有着广泛应用, 更好地服务项目建设。受到地壳运动的影响, 我国部分 地区地震、山洪等地质灾害活跃度高, 影响了人们的日常生活, 给人们带来 了灾害。要想全面避免出现事故, 则需要在项目建设时, 做好有效的测绘, 了解当地的地形地貌特点, 采取有效措施, 全面保证建设安全稳定。对于一 些需要在地质情况复杂的山区施测, 对这样的地区, 就需要全面把握地形 特征, 利用新型地理信息系统技术能够大大提升测量精度, 极大程度保证 了测绘人员安全。新型地理信息系统技术能够全面反映测区情况, 同时, 也能够通过对一个点的集中测绘, 重点反映区域特点, 从団瞰式视角查看 某一地区的地形地貌, 保证了信息的精细化。

新型地理信息系统技术在地形测量中的应用, 需要通过无人机支持, 通过无人机承载多镜头相机, 从高空的视角对地形地貌进行全息采集, 利 用人机图片互换装置对所获取的信息进行数据转码和储存, 传导到后台的 控制中心, 绘制出现状地形图, 为项目建设提供良好的帮助。

2. 4 在城市规划中的应用

地理信息系统对于城市规划测绘来说, 最重要的就是能够为城市规划 测绘提供精确的数据信息内容, 因此, 在城市规划测绘中, 准确的数据测量 是应用地理信息系统的最为基本的要求。工作人员在进行精细准确的测量 时, 只有在对地理信息系统熟悉了解后, 展开合理有效的运用, 才能让地理 信息系统在工程测量时发挥出智能且多变的功能。在具体测绘的时候, 工 作人员可以根据实际测绘的需求对测绘数据进行分析, 这样还可以帮助工 
作人员发现测绘数据上的错误, 保证测绘数据输出的准确度。

2. 5 在资源配置中的应用

首先是环境配置。稳定的施工条件可以帮助项目有序进行, 这是施工 测量的目标和责任。地形信息可以补充工程参数数据库, 优化资源的地理 分布。在施工阶段, 尽管有外部环境因素, 但基于系统的数据支撑, 保证项 目施工条件与外部条件的兼容性, 避免受环境变化的影响。其次, 硬件和软 件。系统具有测量仪器设备和信息处理能力, 具有较好的资源优化能力, 不仅表现在数据管理和硬件状态行运, 也有信息的输入、查询、收集和使 用也可能导致某些操作错误。与此同时, 网络是一个软件环境, 网络的功能 也取决于它们的可访问性。总的来说, 硬件环境和软件环境都需要系统来 确保设备的访问和使用, 以确保系统的稳定性。

三是功能模块。系统具有强大的数据处理功能, 可以轻松转换为不同 格式的信息, 为项目建设过程中提供各种属性信息支撑, 例如图纸施工、工 程制图、工程数据参数等辅助功能不仅可以丰富应用测量数据, 而且数据 值扩大工程测量。系统具有独特的能力, 可以将系统数据库中包含的信息 作为外部悬挂处理, 使其能够更迅速地规划、生产和管理建筑工作。

2. 6 虚拟现实

应急虚拟现实技术是一种全新的测绘技术, 主要是通过模拟虚拟的三 维空间, 带给使用者视觉、听觉、触觉上的模拟, 使其能对事物现状进行实 时判断。在这个过程中, 系统能结合测绘数据制作、采集、融合三维的电 子地图。该技术能在应急演练中创设全新的模式, 如在虚拟情境中对场地 事故进行模拟, 人为制作相应的事故现象, 使参与演练的人员积极响应, 充 分体现演练及培训的功能, 降低投入成本。此系统能分析、模拟事件, 且虚 拟现实技术可结合GPS系统、室内定位系统等其他技术, 将救援者的位置信 息呈现在虚拟现实情境中, 便于制定救援方案或救援指挥。另外, 虚拟现实 应急系统与物联网中的视频监控信息互相集成, 能在三维场景中对视频信 息进行实时调用查看, 详细掌握现场的实际状况。

\section{3 提升新型地理信息系统技术应用效率的措施}

3. 1 提升针对性

在实践应用过程中, 需要全面提升新型地理信息系统技术应用效率, 要根据不同的使用范围, 全面调整适应性、针对性。工程测量应用范围 广泛, 分类多、内容杂。要想保证工程建设的稳定性, 就需要针对性做好 调整, 建筑工程测量对地质、水文条件要求高, 矿区工程测量对矿产分 布、建设难度要求高, 所以说, 只有全面推动新型地理信息系统技术科学 化发展, 开发差异化、针对性技术分支, 才能保证应用效果, 提高工作的 整体效率。

\section{2 推进复合型人才培养}

要想全面实现技术创新, 就需要在人才建设上下功夫, 出台相应的配 套机制, 不断推动人才培养建设。要建立起长效的学习机制, 通过科学的人 才培养, 全面创新技术形态, 这是技术发展的关键。在各种工程测量工作中, 既需要丰富的经验, 更需要知识的积累, 只有把知识转化成应用, 才能保证 工作效率与质量, 在实践过程中, 虽然大部分工程测量人员有丰富地质地 理知识, 但是在应用中, 还没有形成成果的转化, 发挥不出知识的重要作用, 特别是新型地理信息系统技术的应用, 相关人员并不能全面的掌握和应用, 实践过程中还有所不足, 这也就导致了工程测量质量上不去, 效率大大下 降。所以说, 要建设一支理论与实践相结合的人才队五, 全面做好人才的引 进与培养, 才能推动技术创新应用, 大力发展新型地理信息系统技术人才, 在高校进行专业设置, 培养高等人才, 不断强化地质考察相关专业信息技 术学习能力, 为一线提供良好的人才, 全面发挥技术的应用价值, 不断推进 工程测量质量快速发展。

\section{4 地理信息系统技术的发展趋势}

4. 1 现代GIS知识库系统

通过建立GIS知识库系统, 可以对与工程相关的其他领域的数据进行 整合, 包括气候信息、水文信息、人体科学、土工工程等, 进一步提高工程 测量的科学性和准确性, 更好的帮助相关工作者进行决策。

4.2 智能机器人

当前工程测量还需要开展大量的野外测绘工作, 而利用RS、GPS或者 智能机器人等, 可以代替工人, 完成对指定区域的数据采集, 并将实时采 集的数据输入到地理信息系统当中, 进行数据的分析和处理, 不仅降低 了工程测量的危险系数, 保障了相关人员的安全, 而且提高了工程测量 的工作效率。

4. 3 基于 “ $3 \mathrm{R}$ ” 技术的测量系统

通过对GPS、RS和RTX等多种技术进行整合, 建立起全新的地理信息测 量系统, 可以基于信息共享的基础上, 完成对工程的数据测量。GPS全球定 位系统可以利用卫星对地面进行监测, 对环境相对恶劣的区域展开测绘, 提高测绘的精确性。RS技术则利用了遥感影像技术、光学理论等来完成地 理数据信息的采集, 覆盖面积更广, 所获得数据信息也更加全面和精准。RTX 实时动态定位技术则主要通过对参照坐标点的对比, 利用卫星对流动站及 基准值进行实时监测, 以此使数据和信息能够得到及时的更新。

\section{5 结语}

工程测量工作是各项工程开展的首要工作, 只有认真分析工程测量结 果, 并以此进行相应的工程建设设计, 才能够更好地提升工程建设质量和 效率。新型地理信息系统技术在工程测量中的应用能够极大程度地降低人 员工作强度, 提升工程测量效率和准确率。新型地理信息系统在智能城市 建设、地形地貌测绘以及工程变形监测中都有着广泛的应用, 也是我国未 来信息化城市建设的重要推动力, 在未来有着良好的发展前景。但是新型 地理信息系统技术的发展还面临着人员素养不足、机构设置不全面、学科 建设不完善等问题, 在工程测量中还不具备足够的针对性。因此, 新型地理 信息系统技术在未来还有很长的一段路要走, 加强高校科研投入, 推进新 型地理信息系统技术的产业化发展和实验室研究成果转化, 都是推进这一 技术发展的有效路径。新型地理信息系统技术的发展也势必带动工程测量 质量的进步与发展。综上所述, 各种新型地理信息系统技术在测绘工程领 域的运用, 极大程度的激发了工程测量领域的发展。同时, 这些测绘新技术 也存在着不同程度、种类的问题, 需要相关人员对其进行进一步改善。

\section{[参考文献]}

[1]席青杰.新型地理信息系统技术在工程测量中的应用研究 [J].科技 创新与应用,2020,(03):156-157.

[2]刘西岭.浅谈地理信息系统在工程测量中的应用[J].工程建设与设 计,2019,(18):252-253.

[3]张莉.新型地理信息系统技术在工程测量中的应用[J].世界有色金 属,2019,(09):33-34.

[4]尹继业.新型地理信息系统技术在工程测量中的应用分析[J].计算 机产品与流通,2019,(11):278.

[5]王群.新型地理信息系统技术在工程测量中的应用[J].住宅与房地 产,2019,(30):189.

[6]许中胜.地理信息系统技术在工程测量中的应用探讨 [J].现代信息 科技,2019,3(19):24-25.

\section{作者简介:}

张金花(1988--)女, 福建龙岩人, 汉族, 本科学历, 工程师, 从事工作: 工程测量、摄影测量与遥感及地理信息系统等方面工作。 